\title{
Epithelial barrier and ion transport in coeliac sprue: electrical measurements on intestinal aspiration biopsy specimens
}

\author{
J-D Schulzke, I Schulzke, M Fromm, E-O Riecken
}

\begin{abstract}
Epithelial barrier function and ion transport was studied in coeliac sprue using a miniaturised Ussing device for measurements on diagnostic aspiration biopsy specimens from the jejunum of untreated or gluten free nourished sprue patients, or from healthy controls. Pure epithelial resistance $\left(R^{e}\right)$ indicating epithelial barrier function was determined by transmural alternating current impedance analysis. It was reduced by $56 \%$ in acute sprue mean (SEM) (9 (1) $\left.\Omega \cdot \mathrm{cm}^{2}\right)$ compared with controls $\left(20(2) \Omega \cdot \mathrm{cm}^{2}\right)$. In gluten free nourished sprue patients $R^{\mathbf{e}}$ was only partly recovered (15 (1) $\left.\Omega \cdot \mathrm{cm}^{2}\right)$. Subepithelial resistance $\left(R^{\text {sub }}\right)$ was also changed from 28 (1) $\Omega \cdot \mathrm{cm}^{2}-$ in control to 17 (1) $\Omega \cdot \mathrm{cm}^{2}$ in acute sprue because of the change in mucosal architecture, but was unchanged in gluten free nourished sprue patients (29 (4) $\left.\Omega \cdot \mathrm{cm}^{2}\right)$. In acute sprue, unidirectional $\mathrm{Na}^{+}$and $\mathrm{Cl}^{-}$fluxes were increased in both directions as a consequence of the decreased resistance. However, short circuit current $\left(I_{S C}\right)$ as well as $\mathrm{Na}^{+}$and $\mathrm{Cl}^{-}$ net fluxes were not significantly different from control. Subsequently, the electrogenic $\mathrm{Cl}^{-}$secretory system was investigated. After maximal stimulation with theophylline and prostaglandin $\mathrm{E}_{1}, \mathrm{a} \mathrm{Cl}^{-}$dependent increase in I $_{S C}$ was obtained in the sprue mucosa and control jejunum. It showed saturation characteristics and was blockable by serosal bumetanide. When compared with control, neither $K_{m}$ nor $\mathrm{V}_{\text {max }}$ of this electrogenic $\mathrm{Cl}^{-}$secretion was significantly changed in coeliac sprue. In conclusion, a miniaturised Ussing device was used for transport measurements on intestinal biopsy specimens. In acute coeliac disease, the epithelial barrier of the jejunum was seriously disturbed. The active electrogenic $\mathrm{Cl}^{-}$secretory transport system was present in the sprue mucosa, but was not activated in the Ussing chamber in vitro when compared with control jejunum.
\end{abstract}

(Gut 1995; 37: 777-782)

Keywords: coeliac sprue, $\mathrm{Cl}^{-}$secretion, gluten, impedance analysis, jejunum.

Coeliac disease is characterised by gluten sensitivity and hyper-regenerative transformation of the mucosa ('villous atrophy' or 'flat mucosa'). Diarrhoea is one of the most prominent clinical features. Regarding diarrhoeal mechanisms, a reduction in villus area and consequently in $\mathrm{Na}^{+}$-glucose cotransport are important. In addition, the epithelial barrier has been suggested to be impaired in a freeze fracture electron microscopy analysis. ${ }^{1}$ This was supported by in vivo tests, which show an increased intestinal permeability at least for disaccharides. ${ }^{2-4}$ Less information, however, is available on ionic permeability as well as on other active ion transport mechanisms as, for example, electrogenic $\mathrm{Cl}^{-}$secretion. In an in vivo perfusion study a decrease in urea permeability was found, which was taken as evidence for an increased tightness of the sprue mucosa. ${ }^{5}$

The method of choice to study these epithelial functions would have been the Ussing technique, so far never applied to coeliac sprue. This technique offers a defined area reference for the study of the barrier function and permits characterisation of single active transepithelial transport processes. This technique usually requires large pieces of intestine that can only be obtained during surgery. To overcome this problem, a miniaturised chamber was used to study epithelial barrier function and ion transport processes on intestinal aspiration biopsy specimens.

Important results were that the epithelial barrier function was disturbed in acute coeliac sprue and the electrogenic $\mathrm{Cl}^{-}$secretory system was not impaired, although it was not found to be activated in the Ussing chamber in vitro when compared with control.

\section{Experimental groups}

The study was approved by the local ethics committee. Diagnostic biopsies were routinely performed in the university children's hospital. Aspiration biopsy specimens from the jejunum of three groups of children were included: healthy controls, acute coeliac sprue patients, and gluten free nourished sprue patients. The criteria for including children into the healthy control group were: no clinical symptoms at the time of the biopsy and a normal mucosal architecture under normal (gluten containing) diet as well as no gliadin antibodies.

Children were included into the group of acute coeliac sprue who had clinical symptoms of coeliac disease including diarrhoea at the time of the biopsy as well as complete hyperregenerative transformation of the jejunal mucosa ('flat mucosa'). In the subsequent follow up, the diagnosis was confirmed by clinical recovery with a gluten free diet, a 
complete normalisation of the mucosal architecture in jejunal biopsy specimens after one year of gluten free nourishment, and a morphological response to four weeks gluten exposure ( $1 \mathrm{~g}$ per kg body weight daily).

The specimens from the gluten free nourished coeliac sprue patients were obtained after one year of gluten free diet. Criteria for acceptance were: (a) symptoms of coeliac disease and a 'flat mucosa' in the biopsy specimen one year ago, (b) clinical and complete morphological recovery under gluten free diet (that is, specimens showing partial villous atrophy were not included), and (c) a morphological response to four weeks' gluten re-exposure thereafter.

\section{Experimental procedure}

Small pieces of jejunum were obtained during diagnostic biopsies with a Watson system. ${ }^{6}$ They were glued on plastic rings (inner diameter $2.5 \mathrm{~mm}$, outer diameter $4 \mathrm{~mm}$ ), which were subsequently mounted into a modified Ussing chamber allowing for conventional short circuit current and flux measurements as well as alternating current impedance analysis. The time between the biopsy procedure and mounting the tissue into the chamber was about one hour during which the samples were kept in oxygenated, $10 \mathrm{mM}$ glucose containing standard medium at $4^{\circ} \mathrm{C}$. After 10 minutes equilibration in the chamber, impedance analysis and two 10 minute flux periods were performed. Subsequently, the standard medium was changed to a chloride and bicarbonate free medium and then electrogenic $\mathrm{Cl}^{-}$secretion was characterised as described below.

\section{Ussing chamber}

A miniaturised Ussing type chamber designed for impedance measurements on small biopsy specimens was used, which preserves the advantages of conventional low volume, gas lift stirred flux chambers ${ }^{7}$ - that is, an effective circulation of the oxygenated bathing medium for minimising unstirred layers and optimising epithelial oxygen and substrate supply. The chamber was made of Plexiglas and had an opening diameter of $2.5 \mathrm{~mm}$. Sealing of the tissues was provided by soft silicon rubber, thus minimising edge damage. Current electrodes were silver rings located far from the epithelium to form a homogeneous electrical field across the epithelium and to allow for positioning of the voltage electrodes axially within the electrical field. Voltage electrodes were covered by a driven shield and consisted of commercial microelectrode holders (MEH3SF, WP-Instruments, New Haven, CT, USA) connected to glass micropipettes (not pulled; inner/outer diameter $1 \cdot 1 / 1.4 \mathrm{~mm}$; length $25 \mathrm{~mm}$ ). The pipettes were filled with $3 \mathrm{~g} / \mathrm{dl}$ Agar-Agar and $0.5 \mathrm{~mol} / \mathrm{K} \mathrm{KCl}$. Up to a frequency of $3 \mathrm{kHz}$ this Ussing type chamber (including electrodes and amplifiers) exhibited no significant deviation from 'ideal' ohmic characteristics. Above $3 \mathrm{kHz}$ there was increasing but still very small inherent capacitive properties. At the highest frequency used $65 \mathrm{kHz}$, the imaginary part of the impedance of the fluid filled chamber (without tissue) was $-3 \Omega \cdot \mathrm{cm}^{2}$. These deviations were corrected for in each single experiment (see later).

\section{Alternating current impedance measurements} Impedance analysis was performed as introduced previously ${ }^{8-12}$ using a programmable 1250 frequency response analyser in combination with a 1286 electrochemical interface (Solartron Schlumberger, Farnborough, Hampshire). Sine wave alternating currents (35 $\mu \mathrm{A} / \mathrm{cm}^{2}$ eff) in the range of $1 \mathrm{~Hz}$ to $65 \mathrm{kHz}$ were applied and the voltage responses detected. Each impedance measurement consisted of 48 measurements at increasing frequency and took about one minute. The complex impedance was calculated on line and stored on the hard disk of a personal computer. The impedance locus was plotted in a Nyquist diagram. Correction for the impedance of the experimental set up was performed by measuring the impedance of the fluid filled chamber and subtracting it for each frequency from subsequently measured impedance data. Correction was done by vector subtraction in the complex impedance plane. This procedure also included correction for bath resistance.

\section{Discrimination of epithelial and subepithelial resistance}

Discrimination of epithelial and subepithelial resistance by impedance analysis was performed as described earlier. ${ }^{8-12}$ Briefly, for each impedance locus plot a circle segment was fitted to the data points by least square analysis. From this circle segment three parameters of a lumped electrical equivalent circuit were obtained, modelling the epithelium as a unit of a resistor $\left(R^{e}\right)$ and a capacitor $\left(C^{e}\right)$ in parallel and the subepithelium as a resistance ( $\mathbf{R}^{\text {sub }}$ ) in series to this RC unit. ${ }^{13}$ Thus, the impedance technique discriminates between the epithelial $\left(\mathbf{R}^{\mathrm{e}}\right)$ and the subepithelial $\left(\mathbf{R}^{\mathrm{sub}}\right)$ contribution to the total wall resistance $\left(R^{t}\right)$.

\section{$\mathrm{ISC}_{\mathrm{SC}}$ and $\mathrm{Na}^{+}$and $\mathrm{Cl}^{-}$fluxes}

Short circuit current $\left(\mathrm{I}_{\mathrm{SC}}\right)$, tissue resistance, and unidirectional $\mathrm{Na}^{+}$and $\mathrm{Cl}^{-}$fluxes were measured using the Ussing technique ${ }^{14}$ as described by Schultz and Zalusky. ${ }^{7}$ The standard medium contained (mM): $\mathrm{Na}^{+} 140$, $\mathrm{Cl}^{-} 123 \cdot 8, \mathrm{~K}^{+} 5 \cdot 4, \mathrm{HPO}_{4}{ }^{2-} 2 \cdot 4, \mathrm{H}_{2} \mathrm{PO}_{4}{ }^{-} 0 \cdot 6$, $\mathrm{Ca}^{2+} 1 \cdot 2, \mathrm{Mg}^{2+} 1 \cdot 2, \mathrm{HCO}_{3}-21$ (gassed with $95 \% \mathrm{O}_{2}$ and $5 \% \mathrm{CO}_{2} ; \mathrm{pH} 7.4$ at $37^{\circ} \mathrm{C}$ ). The absence of significant drift of the voltage electrodes was checked at the end of each experiment. All $\mathrm{I}_{\mathrm{SC}}$ values were corrected for bath resistance as described by Tai and Tai. ${ }^{15}$ For calculating net fluxes the tissues were matched for tissue resistance.

\section{Electrogenic $\mathrm{Cl}^{-}$secretion}

Transport capacity of electrogenic $\mathrm{Cl}^{-}$ 
secretion was characterised as described earlier ${ }^{111216}$ following a protocol of Heintze et al. ${ }^{17}$ Initially the tissue was in a $\mathrm{Cl}^{-}$and $\mathrm{HCO}_{3}{ }^{-}$free medium (in $\mathrm{mM}: \mathrm{Na}^{+} 125 \cdot 4$, $\mathrm{SO}_{4}{ }^{2-} 65 \cdot 1, \mathrm{~K}^{+} 5 \cdot 4, \mathrm{HPO}_{4}{ }^{2-} 2 \cdot 4, \mathrm{H}_{2} \mathrm{PO}_{4}{ }^{-}$ $0 \cdot 6, \mathrm{Ca}^{2+} 1 \cdot 2 . \mathrm{Mg}^{2+} 1 \cdot 2$, TRIS 4, HEPES 4, and mannitol 120 , gassed with $100 \% \mathrm{O}_{2}, \mathrm{pH}$ 7.4 at $37^{\circ} \mathrm{C}$ ). The tissues were stimulated by prostaglandin $\mathrm{E}_{1}(10 \mu \mathrm{M})$ plus theophylline $(10 \mathrm{mM})$ on both sides. Then, the increase in $\mathrm{I}_{\mathrm{SC}}\left(\Delta \mathrm{I}_{\mathrm{SC}}\right)$ was measured after (mucosal and serosal) addition of $\mathrm{Cl}^{-}$. Solutions were always identical on both sides of the Ussing chamber to avoid dilution potentials. The $\mathrm{Cl}^{-}$concentration was raised in about five minute intervals by partly replacing the $\mathrm{Cl}^{-}$and $\mathrm{HCO}_{3}{ }^{-}$free medium by a medium containing $120 \mathrm{mM} \mathrm{Cl}^{-}$ instead of $60 \mathrm{mM} \mathrm{SO}_{4}{ }^{2-}$ and $60 \mathrm{mM}$ mannitol. This resulted in final $\mathrm{Cl}^{-}$concentrations of
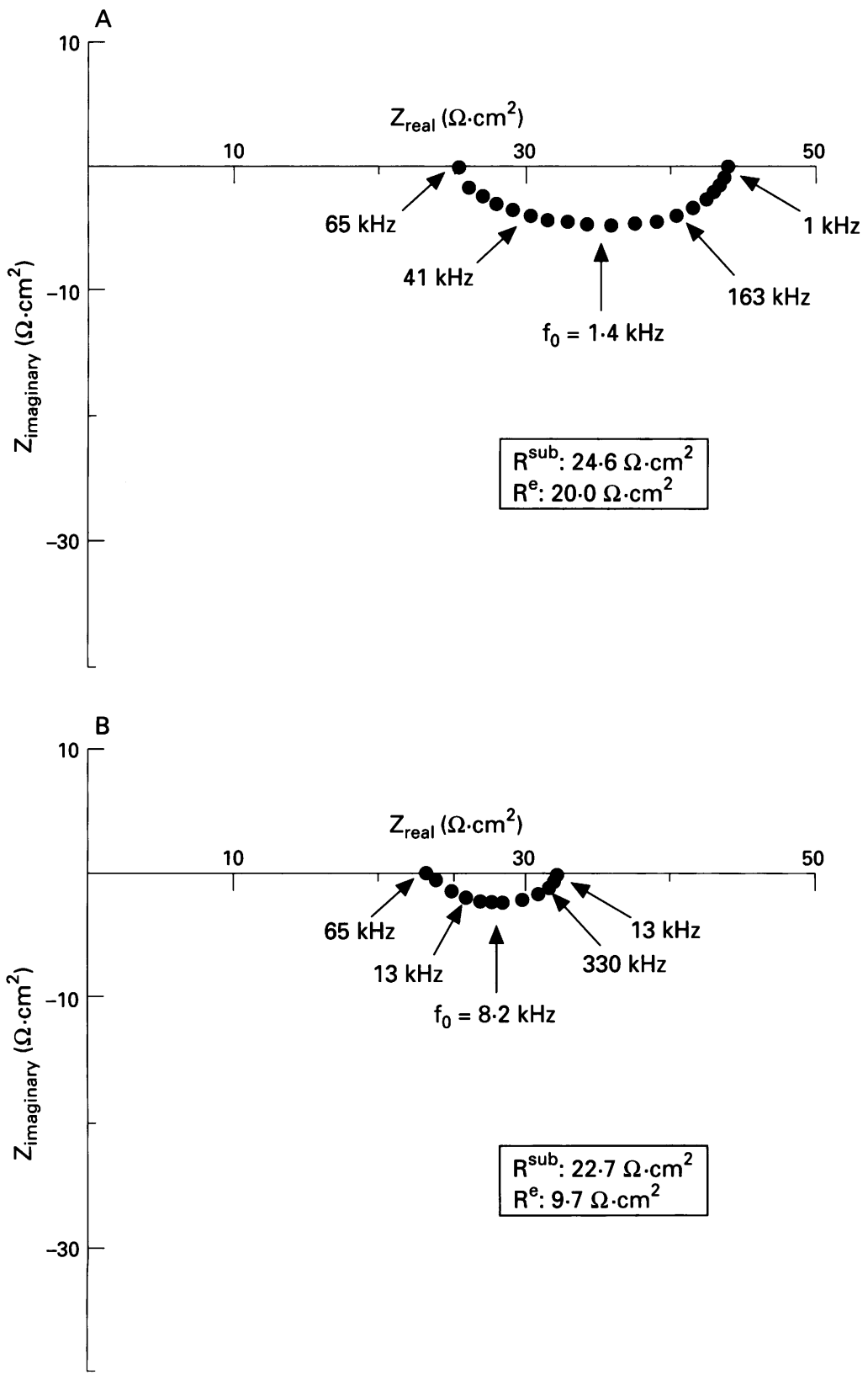

Figure 1: Original impedance locus plots of human jejunum. (A) Control, (B) acute coeliac sprue. $Z_{\text {real }}$ gives the ohmic component and $Z_{\text {imanary }}$ the reactive component of the complex impedance. Intersections between semicircle and $x$ axis at low and high frequencies represent total resistance $\left(R^{\mathrm{t}}\right)$ and subepithelial resistance $\left(R^{\mathrm{sub}}\right)$, respectively. $R^{\mathrm{t}}$ minus $R^{\text {sub }}$ gives the resistance of the epithelium $\left(R^{e}\right)$. For a detailed explanation of transepithelial impedance data see refs 8-13.
10, 20, and $40 \mathrm{mM} . \Delta \mathrm{I}_{\mathrm{SC}}{ }^{\max }\left(\mathrm{V}_{\max }\right)$ and $\mathrm{K}_{\mathrm{m}}$ were determined from the reciprocal plot (Lineweaver and Burk) for each specimen separately. Thereafter $\Delta \mathrm{I}_{\mathrm{SC}}{ }^{\max }$ and $\mathrm{K}_{\mathrm{m}}$ were calculated for each experimental group. At the end of each experiment the decrease in $\mathrm{I}_{\mathrm{SC}}$ after serosal addition of bumetanide $(10 \mu \mathrm{M})$ was measured.

\section{Conventional histological examination}

The thickness of the subepithelial tissue including villus core was measured in haematoxylin and eosin stained cross sections.

\section{Statistics}

All data are mean (SEM). The statistical evaluation is based on Student's $t$ test for unpaired data, $p<0.05$ was considered significant.

\section{Results}

Alternating current impedance measurements In Fig 1 original impedance locus plots of control jejunum (Fig 1A) and acute coeliac sprue (Fig 1B) are shown and the statistical analysis of the impedance measurements is given in Table I. In control jejunum, epithelial and subepithelial resistance was $20(2) \Omega \cdot \mathrm{cm}^{2}$ and 28 (1) $\Omega \cdot \mathrm{cm}^{2}$, respectively. Thus, subepithelial resistance contributed almost $60 \%$ to the total wall resistance in jejunal aspiration biopsy specimens. This, however, is in line with previous findings of a subepithelial resistance contribution of more than $80 \%$ to the overall wall resistance in (intact) rat jejunum still containing the muscularis propria ${ }^{9}$ and further supports the view that the proximal small intestine is one of the most conductive epithelia.

When compared with control, the jejunum from acute coeliac sprue patients showed a decrease in epithelial resistance by $56 \%$ (from 20 (2) $\Omega \cdot \mathrm{cm}^{2}$ in control to 9 (1) $\Omega \cdot \mathrm{cm}^{2}$ in acute coeliac sprue). Concomitantly, subepithelial resistance was also reduced from 28 (1) $\Omega \cdot \mathrm{cm}^{2}$ in control to 17 (1) $\Omega \cdot \mathrm{cm}^{2}$ acute coeliac sprue.

In gluten free nourished coeliac sprue patients epithelial resistance was only partly recovered (15 (1) $\Omega \cdot \mathrm{cm}^{2}$ ) when compared with acute coeliac sprue patients, while subepithelial resistance was restored to normal (29 (4) $\Omega \cdot \mathrm{cm}^{2}$ ).

TABLE I Epithelial and subepithelial contributions to transmural electrical resistance in coeliac sprue

\begin{tabular}{lclll}
\hline & $R^{\mathrm{e}}$ & $R^{\text {sub }}$ & $R^{\mathrm{t} / R^{\mathrm{e}}}$ & No \\
\hline Control & $20(2)$ & $28(1)$ & $2 \cdot 4(0 \cdot 3)$ & 9 \\
Coeliac sprue (acute) & $9(1)^{\star \star \star}$ & $17(1)^{\star \star \star}$ & $3 \cdot 0(0 \cdot 6) \dagger$ & 9 \\
$\begin{array}{l}\text { Coeliac sprue (gluten } \\
\text { free) }\end{array}$ & $15(1)^{\star}$ & $29(4) \dagger$ & $2 \cdot 9(0 \cdot 3) \dagger$ & 6 \\
\hline
\end{tabular}

Epithelial $\left(R^{\mathrm{e}}, \Omega \cdot \mathrm{cm}^{2}\right)$ and subepithelial resistance $\left(R^{\text {sub }}\right.$, $\Omega \cdot \mathrm{cm}^{2}$ ) as determined by impedance analysis in controls, acute coeliac sprue, and gluten free nourished coeliac sprue patients. Total intestinal wall resistance $\left(R^{t}\right)$ is the sum of $R^{e}$ and $R^{\text {sub }} \cdot \mathbf{R}^{t} / \mathbf{R}^{\mathrm{e}}$ is the correction factor of active transport rates (I $\mathrm{I}_{\mathrm{SC}}$ and net fluxes) for the contribution of subepithelial resistance (see Methods). All values are means (SEM). $\star=p<0.05,{ }^{\star \star \star}=p<0.001, \dagger=$ not significantly different from control. 
TABLE II $\mathrm{Na}^{+}$and $\mathrm{Cl}^{-}$fluxes in coeliac sprue

\begin{tabular}{|c|c|c|c|c|c|c|c|}
\hline & $I_{\mathrm{SC}}$ & $\mathcal{F}_{\mathrm{Na}}{ }^{\text {net }}$ & $\mathfrak{f}_{\mathrm{Na}}{ }^{\mathrm{ms}}$ & $\mathcal{F}_{\mathrm{Na}}{ }^{\mathrm{sm}}$ & $\mathcal{F}_{\mathrm{Cl}}^{\text {net }}$ & $\mathcal{F}_{\mathrm{Cl}}^{\mathrm{ms}}$ & $\mathcal{f}_{\mathrm{Cl}}^{\mathrm{sm}}$ \\
\hline $\begin{array}{l}\text { Raw data } \\
\text { Control } \\
\text { Sprue } \\
\text { p Value } \\
\text { After correctio } \\
\text { Control } \\
\text { Sprue } \\
\text { p Value }\end{array}$ & $\begin{array}{l}1.3(0.3) \\
1.3(0.3) \\
\text { NS } \\
\text { on } \\
3 \cdot 2(0.8) \\
3.8(1 \cdot 1) \\
\text { NS }\end{array}$ & $\begin{array}{l}0 \cdot 1(0 \cdot 8) \\
0 \cdot 1(2 \cdot 2) \\
\text { NS } \\
\\
0 \cdot 2(1 \cdot 9) \\
0 \cdot 2(6 \cdot 7) \\
\text { NS }\end{array}$ & $\begin{array}{l}9 \cdot 6(1 \cdot 1) \\
14 \cdot 5(2 \cdot 1) \\
\text { NS }\end{array}$ & $\begin{aligned} & 9.5(1.0) \\
& 14.5(0.8) \\
&<0.01\end{aligned}$ & $\begin{array}{l}0.1(0.4) \\
0.0(2.3) \\
\text { NS } \\
\\
0 \cdot 2(1.0) \\
0.0(6.9) \\
\text { NS }\end{array}$ & $\begin{array}{l}9 \cdot 3(1 \cdot 6) \\
14 \cdot 3(3 \cdot 0) \\
\text { NS }\end{array}$ & $\begin{array}{l}9.2(1.4) \\
14.3(1.2) \\
<0.05\end{array}$ \\
\hline
\end{tabular}

Short circuit current $\left(I_{S C} ; n=9\right)$ and $\mathrm{Na}^{+}$and $\mathrm{Cl}^{-}$fluxes $(J)$ in $\mu \mathrm{mol} \cdot \mathrm{h}^{-1} \cdot \mathrm{cm}^{-2}(\mathrm{~ms}=$ mucosa to serosa, $\mathrm{sm}=$ serosa to mucosa; $\mathrm{n}=4$ ) in controls and acute coeliac sprue. I $\mathrm{SC}$ and net fluxes are given before (raw data) and after correction for subepithelial resistance contributions as

described under Results. Values are means (SEM). NS=not significantly different.

Before transport data of control and coeliac sprue can be compared, correction is necessary for the respective subepithelial resistance contributions.* Generally, after correction for the bathing solution, the factor by which the measured transport rate underestimates the true active transport is given by the ratio of total wall resistance over epithelial resistance $\left(R^{t} / R^{e}\right) .^{8-12151819} R^{t} / R^{\mathrm{e}}$ was $2 \cdot 4$ in control, $3 \cdot 0$ in acute coeliac sprue, and 2.9 in the jejunum of gluten free nourished sprue patients (NS Table I), which means that measured $\mathrm{I}_{\mathrm{SC}}$ and net fluxes considerably underestimate true transport rates. However, $R^{t} / R^{e}$ was similar and consequently the degree of underestimation proportional in all three groups.

$I_{\mathrm{SC}}$ and $\mathrm{Na}^{+}$and $\mathrm{Cl}^{-}$fluxes

Table II summarises the data. In control jejunum, there was a (positive) short circuit current $\left(\mathrm{I}_{\mathrm{SC}}\right)$ and ms- and sm-fluxes of $\mathrm{Na}^{+}$ and $\mathrm{Cl}^{-}$were of the same magnitude. Thus, net fluxes for $\mathrm{Na}^{+}$and $\mathrm{Cl}^{-}$flux were not significantly different from zero. There are two reasons why the net $\mathrm{Na}^{+}$and $\mathrm{Cl}^{-}$fluxes in the

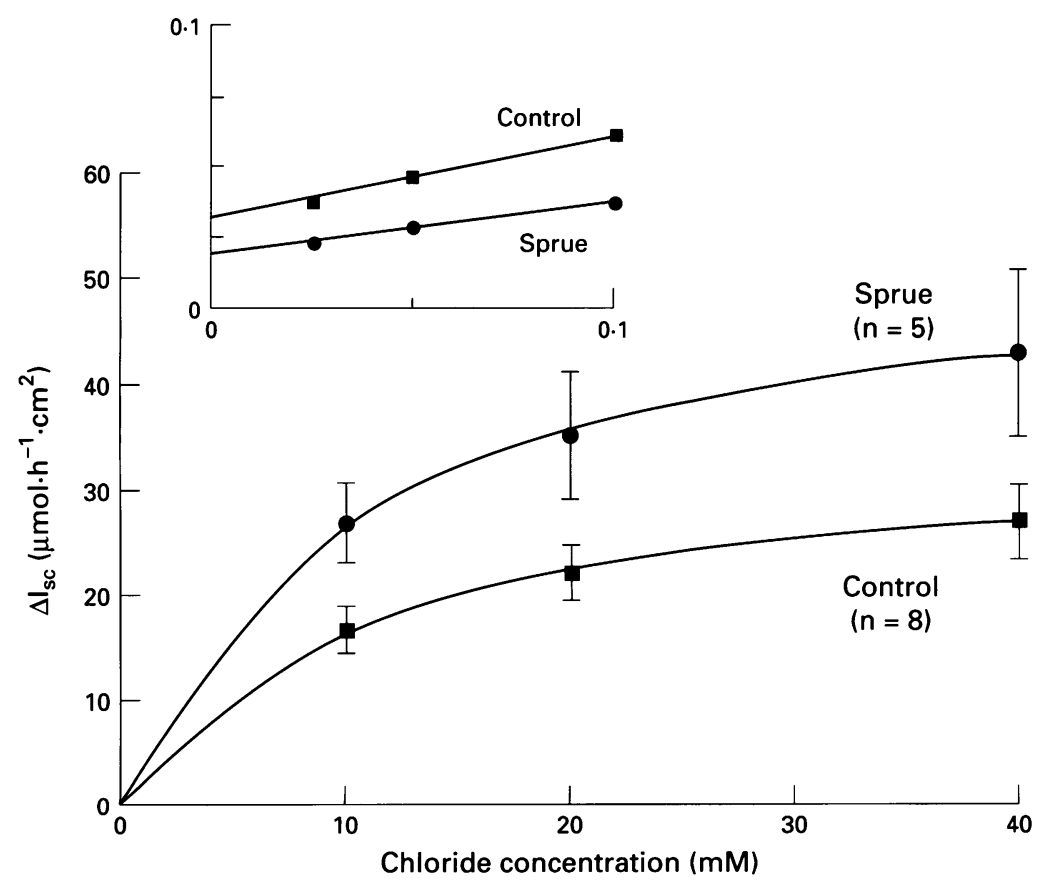

Figure 2: Electrogenic $\mathrm{Cl}^{-}$secretory system in coeliac sprue. Increase in short circuit current $\left(\Delta I_{S C}\right)$ as a function of the $\mathrm{Cl}^{-}$concentration in the bathing medium in control jejunum and acute coeliac sprue mucosa. Tissues are stimulated by $10 \mu M$ prostaglandin $E_{1}$ and $10 \mathrm{mM}$ theophylline, to characterise their maximal transport capacity. Data were corrected for subepithelial resistance contributions. The inset shows the reciprocal plot of the same data. $\Delta I_{\mathrm{SC}} \max \left(V_{\mathrm{max}}\right)$ was $1.3(0 \cdot 2) \mu \mathrm{mol} / \mathrm{h}^{-1} \mathrm{~cm}^{-2}(n=8)$ in control and 2.0 $(0 \cdot 6) \mu \mathrm{mol} \cdot \mathrm{h}^{-1} \cdot \mathrm{cm}^{-2}(n=5 ; \mathrm{NS})$ in coeliac sprue. $K_{\mathrm{m}}$ was 12 (3) $\mathrm{mM}$ in control and 10 (2) $m M(N S)$ in coeliac sprue. jejunum measured with the Ussing technique were not significantly different from zero (in the presence of a positive $\mathrm{I}_{\mathrm{SC}}$ ) as has also been obtained in other studies. ${ }^{1120}$ Firstly, active transport is superposed by large diffusional movements of ${ }^{22} \mathrm{Na}^{+}$and ${ }^{36} \mathrm{Cl}^{-}$through the highly conductive paracellular pathway in this very leaky epithelium making it difficult to detect small active transport rates. Secondly, epithelial resistance is less than half of total resistance. Therefore, most of the actively transported ions diffuse back according to the epithelial/ subepithelial resistance ratio (see above).

As significant net fluxes were not detectable in our study it was impossible to draw any conclusion regarding the ionic basis of $\mathrm{I}_{\mathrm{SC}}$. In the jejunum of the rat Munck $^{20}$ investigated the ionic basis of $\mathrm{I}_{\mathrm{SC}}$ by means of $\mathrm{I}_{\mathrm{SC}}$ measurements during ion substitution. He found that $\mathrm{I}_{\mathrm{SC}}$ can be accounted for to one third by electrogenic $\mathrm{Na}^{+}$absorption and to two thirds by electrogenic $\mathrm{Cl}^{-}$secretion (while net flux was also not significantly different from zero). Although not studied in this paper, it may be reasonable to assume that these two transport systems are responsible for $\mathrm{I}_{\mathrm{SC}}$ also in the jejunum of humans.

In acute coeliac sprue, the jejunum exhibited a decrease in total resistance (see Table I) as a consequence of which (and in support of which) unidirectional $\mathrm{Na}^{+}$and $\mathrm{Cl}^{-}$fluxes were increased in both directions ( $\mathrm{ms}$ and $\mathrm{sm}$ ). Net fluxes for $\mathrm{Na}^{+}$and $\mathrm{Cl}^{-}$, however, were again not significantly different from zero (see above). When compared with control jejunum, all active transport rates including $\mathrm{I}_{\mathrm{SC}}$ and net $\mathrm{Na}^{+}$and $\mathrm{Cl}^{-}$fluxes were not significantly changed in acute coeliac sprue even after correction for the respective subepithelial resistances (Table II).

\section{Electrogenic $\mathrm{Cl}^{-}$secretion}

The electrogenic $\mathrm{Cl}^{-}$secretory system was investigated after maximal stimulation by simultaneous addition of theophylline and prostaglandin $\mathrm{E}_{1}$. In both control jejunum and acute sprue, after addition of $\mathrm{Cl}^{-}$to the $\mathrm{Cl}^{-}$ free bathing solution $\mathrm{I}_{\mathrm{SC}}$ increased (Fig 2). This $\mathrm{Cl}^{-}$dependent increase in $\mathrm{I}_{\mathrm{SC}}$ was saturable and in the reciprocal plot the data fit a straight line indicating Michaelis-Menten kinetics. $\mathrm{K}_{\mathrm{m}}$ was not different between control jejunum (12 (3) $\mathrm{mM}, \mathrm{n}=8$ ) and acute coeliac sprue (10 (2) $\mathrm{mM}, \mathrm{n}=5, \mathrm{NS}) . \Delta \mathrm{I}_{\mathrm{SC}}{ }^{\max }\left(\mathrm{V}_{\text {max }}\right)$ was $1.3(0 \cdot 2) \mu \mathrm{mol} \cdot \mathrm{h}^{-1} \cdot \mathrm{cm}^{-2}(\mathrm{n}=8)$ in control jejunum and was not significantly different in acute coeliac sprue $\left(2 \cdot 0(0 \cdot 6) \mu \mathrm{mol} \cdot \mathrm{h}^{-1} \cdot \mathrm{cm}^{-2}\right.$, $\mathrm{n}=5$, NS, data were corrected for subepithelial resistance as described under Methods). Furthermore, the increase in $\mathrm{I}_{\mathrm{SC}}$ after addition of $\mathrm{Cl}^{-}$was reversible by serosal addition of bumetanide $(10 \mu \mathrm{M})$. Bumetanide blocked $91 \%$ of $\Delta \mathrm{I}_{\mathrm{SC}}$ in control jejunum and $86 \%$ in acute coeliac sprue.

ॠWhenever in addition to the epithelial resistance significant nonepithelial series resistances are present between the voltage sensing epithelial series resistances are present between the voltage sensing electrodes, measured I $\mathrm{SC}$ or net fluxes have to be corrected for the contribution of these resistances. This is well known for the bath resistance, but is necessary for the subepithelial resistance of intestinal preparations as well. The implications of this correction 
Conventional histological examination

Conventional histological examination on cross sectioned specimens was performed to define the cutting plane of the aspiration biopsy procedure. It turned out that aspiration biopsy specimens were disconnected within the submucosa. Thus, it cannot be assumed that the submucosal plexus was functionally preserved in Ussing experiments.

Because of the loss of villi in acute coeliac disease (flat mucosa) the overall thickness of the subepithelial tissue layers including villus core was decreased from 456 (13) $\mu \mathrm{m}(\mathrm{n}=7)$ in control to 233 (14) $\mu \mathrm{m}(\mathrm{n}=6, \mathrm{p}<0.001)$ in the acute sprue mucosa. This is the structural correlate of the decrease in subepithelial resistance (see above).

\section{Discussion}

\section{Electrophysiological measurements on biopsy specimens}

A miniaturised Ussing chamber was constructed that enabled us to carry out measurements on intestinal biopsy specimens obtained with the Watson system. This chamber not only permitted $\mathrm{I}_{\mathrm{SC}}$ and flux measurements but also alternating current impedance measurements. Impedance analysis was a prerequisite for interpreting resistance and transport data for two reasons. Firstly, studies were performed on specimens, which may be complicated by a varying thickness of their subepithelial layers. Secondly, the 'flat sprue mucosa' had to be compared with control jejunum, which means that mucosae at different stages of intestinal transformation had to be compared. While conventional direct current techniques permit only measurement of total resistance, impedance analysis enables us to measure epithelial resistance in the presence of subepithelial tissue. Thus, correction factors of active transport rates ( $\mathrm{I}_{\mathrm{SC}}$ and net fluxes) for the contribution that is made by subepithelial resistance can also be calculated (see Results). We have used impedance analysis previously to characterise epithelial barrier and transport function under pathological conditions. These studies were performed in the blind loop syndrome ${ }^{11}$ and in the short bowel syndrome, ${ }^{12}$ where mucosae at different stage of mucosal transformation also had to be compared.

\section{Alternating current impedance measurements}

The epithelium is the main barrier between the intestinal lumen and the vascular compartment, as capillaries with their highly permeable endothelium ${ }^{21}$ are located in near proximity to the enterocytes. In coeliac disease, epithelial barrier function was seriously affected. Epithelial resistance decreased from 20 to 9 $\Omega \cdot \mathrm{cm}^{2}$. The barrier disturbance, however, is even considerably more pronounced than shown by this $56 \%$ decrease in epithelial resistance, as the reduced villous surface area ('flat mucosa') - although partly compensated by the enlarged crypt cell compartment - is itself accompanied by an increase in resistance per square centimetre. Taking this geometrical factor into account it is reasonable to assume that the epithelial barrier defect is an important functional feature of the small intestine in coeliac disease. In gluten free nourished coeliac sprue patients epithelial resistance was partly recovered to $15 \Omega \cdot \mathrm{cm}^{2}$, although not restored to normal.

\section{$\mathrm{Na}^{+}$and $\mathrm{Cl}^{-}$fluxes and short circuit current (ISC)}

Previous in vivo perfusion studies have detected a shift of $\mathrm{Na}^{+}$and $\mathrm{Cl}^{-}$movement towards secretion in coeliac disease, which was sometimes taken as evidence for the activation of active secretory systems such as electrogenic $\mathrm{Cl}^{-}$secretion. ${ }^{522} 23 \mathrm{~A}$ shift towards secretion in in vivo perfusion experiments, however, does not necessarily require activation of active secretory systems. Instead, passive secretion could be elicited by epithelial barrier dysfunction, as passive gradients, for example, a high $\mathrm{Na}^{+}$concentration in the villus core established by the counter current mechanism of the villus are not eliminated in in vivo perfusion studies. 182425 Furthermore, the decreased absorptive transport rates as caused by the reduced surface area in coeliac sprue may have contributed to the shift of net transport towards secretion.

Therefore, this study aimed to yield direct evidence for active $\mathrm{Cl}^{-}$secretion in acute coeliac disease. Surprisingly, in these Ussing experiments no hint for the induction of active ion secretion in coeliac disease could be detected. Neither did absolute values for net $\mathrm{Na}^{+}$and $\mathrm{Cl}^{-}$fluxes point to active secretion nor was there a significant shift towards secretion when compared with control. While net flux measurements are of limited sensitivity because of the small number of tissues studied, the large diffusional movements of ${ }^{22} \mathrm{Na}^{+}$and ${ }^{36} \mathrm{Cl}^{-}$in the very leaky jejunum and the significant subepithelial resistance barrier (see Results), $I_{S C}$ is much more sensitive in this respect. The finding that $\mathrm{I}_{\mathrm{SC}}$ was not increased suggests that electrogenic $\mathrm{Cl}^{-}$secretion is not activated in the mucosa of acute coeliac sprue patients.

This does not completely rule out, however, that active $\mathrm{Cl}^{-}$secretion may play a part in coeliac disease in vivo. Firstly, conventional histological examination showed that the plexus Auerbach and Meissner are absent in aspiration biopsy specimens. The enteric nervous system, however, could be important in mediating a secretory response. Secondly, it cannot be excluded that other mediators of secretion, such as prostaglandins or cytokines, are liberated only in vivo and not in vitro when blood flow is interrupted. On the other hand, tissue samples from patients with inflammatory bowel disease have shown changes in transport after transferring into the Ussing chamber. ${ }^{26}$ Taking this into account, our data do not support a contribution of active $\mathrm{Cl}^{-}$secretion in coeliac sprue. 
Impaired $\mathrm{Cl}^{-}$secretory system?

Finally, the question arose whether the lack of secretion in our Ussing experiments could have resulted from the absence or disturbance of the electrogenic $\mathrm{Cl}^{-}$secretory system in the hyper-regeneratively transformed sprue mucosa, as is the case for the $\mathrm{Na}^{+}$-glucose cotransport system. While the reduction in $\mathrm{Na}^{+}$-glucose cotransport is caused by reduced villus surface area in untreated coeliac sprue, electrogenic $\mathrm{Cl}^{-}$secretion could be handicapped by cell immaturity of the crypt enterocytes in the hyper-regeneratively transformed mucosa. To check the maximal transport rate of the electrogenic $\mathrm{Cl}^{-}$secretory system, stimulation was performed with theophylline plus prostaglandin $\mathrm{E}_{1}$. It was shown for the first time in this study that the electrogenic $\mathrm{Cl}^{-}$ secretory system was not impaired in the acute stage of coeliac disease. The tendency of a higher electrogenic $\mathrm{Cl}^{-}$secretion transport capacity could be caused by the increased crypt cell mass of the hyper-regeneratively transformed mucosa in coeliac sprue, but this did not reach statistical significance. Taken together, the lack of spontaneous $\mathrm{Cl}^{-}$secretion in the untreated sprue mucosa is not caused by damage to this transport system, but is by a lack of activation.

This work was supported in part by the Deutsche Forschungsgemeinschaft (Schu 559/2-2 and Schu 559/4-1). We thank P Clausen, A Fromm, U Lempart, and S Lüderitz for thank P Clausen, A Fromm, U Lem

1 Madara JL, Trier JS. Structural abnormalities of jejunal epithelial cell membranes in celiac sprue. Lab Invest 1980; 43: 254-61.

2 Cobden I, Dickinson RJ, Rothwell J, Axon ATR. Intestinal permeability assessed by excretion ratios of two permeability assessed by excretion ratios of two

3 Menzies IS, Laker MF, Pounder R, Bull J, Heyer S, Wheeler PG, et al. Abnormal intestinal permeability to sugars in villous atrophy. Lancet 1979 ; ii: 1107-9.

4 Ukabam SO, Cooper BT. Small intestinal permeability to mannitol, lactulose, and polyethylene glycol 400 in celiac disease. Dig Dis Sci 1984; 29: 809-16.

5 Fordtran JS, Rector FC, Locklear TW, Ewton MF. Water and solute movement in the small intestine of patients with sprue. 7 Clin Invest 1967; 46: 287-98.

6 McCarthy CF, Gough KR, Rodriguez M, Read AE. Peroral intestinal mucosal biopsy with a small Crosby capsule. $B M \Im$ 1964; 1: 1620 .
7 Schultz SG, Zalusky R. Ion transport in isolated rabbit ileum. F Gen Physiol 1964; 47: 567-84.

8 Fromm M, Palant C, Bentzel C, Hegel U. Protamine reversibly decreases paracellular cation permeability in reversibly decreases paracellular cation permeability in
Necturus gallbladder. $₹$ Membr Biol 1985; 87: 141-50.

9 Fromm M, Schulzke JD, Hegel U. Epithelial and subepithelial contributions to transmural electrical resistance of intact rat jejunum, in vitro. Pflügers Arch 1985; 405: 400-2.

10 Schulzke JD, Fromm M, Hegel U. Epithelial and subepithelial resistance of rat large intestine: segmental differences, effect of stripping, time course, and action of aldosterone. Pflügers Arch 1986; 407: 623-7.

11 Schulzke JD, Fromm M, Menge H, Riecken EO. Impaired intestinal sodium and chloride transport in the blind loop syndrome of the rat. Gastroenterology 1987; 92: 693-8.

12 Schulzke JD, Fromm M, Bentzel CJ, Zeitz M, Menge $H$ Riecken EO. Epithelial ion transport in the experimental short bowel syndrome of the rat: increased glucosedependent. Na-absorption is the main adaptive response. dependent. Na-absorption is the main
Gastroenterology 1992; 102: 497-504.

13 Schifferdecker E, Frömter E. The AC impedance of Necturus gallbladder epithelium. Pflügers Arch 1978; 377: 125-33.

4 Ussing $\mathrm{HH}$, Zerahn $\mathrm{K}$. Active transport of sodium as the source of electric current in the short-circuited isolated frog skin. Acta Physiol Scand 1951; 23: 110-27.

15 Tai YH, Tai CY. The conventional short-circuiting technique under-short-circuits most epithelia. $\mathcal{f} \mathrm{Membr}$ Biol 1981; 59: 173-7.

16 Schulzke JD, Fromm M, Hegel U, Riecken EO. Ion transport and enteric nervous system (ENS) in rate rectal colon: mechanical stretch causes electrogenic Cl-secretion via plexus Meissner and amiloride-sensitive electrogenic Na-absorption is not affected by intramural neurons. Pflügers Arch 1989; 414: 216-21

17 Heintze K, Stewart CP, Frizzell RA. Sodium-dependent chloride secretion across rabbit descending colon. $A m \mathcal{F}$ Physiol 1983; 244: G357-65.

18 Groot JA, Bakker R. $\mathrm{NaCl}$ transport in the vertebrate intestine. In: Greger R, ed. Advances in comparative and environmental physiology. Berlin: Springer-Verlag, 1988; 1: environment $103-52$.

19 Hegel U, Fromm M. Electrical measurements in large intestine (including caecum, colon, rectum). In: intestine (including caecum, colon, rectum). In: Fleischer S, Fleischer B, eds. Methods in enzym

20 Munck BG. Effects of sugar and amino acid transport on transepithelial fluxes of sodium and chloride of shortcircuited rat jejunum. F Physiol 1972; 223: 699-717.

21 Palade GE, Simionescu M, Simionescu N. Structural aspects of the permeability of the microvascular endothelium. Acta Physiol Scand 1979463 (suppl): 11-32.

22 Schmid WC, Phillips SF, Summerskill WHJ. Jejunal secretion of electrolytes and water in non-tropical sprue. $\mathcal{f} L a b$ tion of electrolytes and wate

23 Bloch $R$, Menge $H$, Lingelbach $B$, Lorenz-Meyer $H$, Haberich FJ, Riecken EO. The relationship between structure and function of small intestine in patients with a sprue syndrome and in healthy controls. Klin Wochenschr 1973; 51: 1151-8.

24 Jodal M, Hallbäck DA, Lundgren O. Tissue osmolality in intestinal villi during luminal perfusion with isotonic electrolyte solutions. Acta Physiol Scand 1978; 102: 94-107.

25 Sjöqvist A Beeuwkes $R$ Villus and crypt electrolyte and fluid transport during intestinal secretion. Acta Physiol Scand 1990; 139: 203-10.

26 Archampong EQ, Harris J, Clark CG. The absorption and secretion of water and electrolytes across the healthy and the diseased human colonic mucosa measured in vitro. Gut 1972; 13: 880-6. 